See discussions, stats, and author profiles for this publication at: https://www.researchgate.net/publication/269089035

\title{
Design of a reconfigurable Li-Ion Battery Management System (BMS)
}

Conference Paper · June 2014

DOI: 10.1109/TAEE.2014.6900162

CITATION

1

5 authors, including:

Jose Maria Cabrera

Universidad de Las Palmas de Gran Canaria

7 PUBLICATIONS 4 CITATIONS

SEE PROFILE

F) Himar Fabelo

Universidad de Las Palmas de Gran Canaria

52 PUBLICATIONS 422 CITATIONS

SEE PROFILE

Some of the authors of this publication are also working on these related projects:

UAV design optimzation View project

[Helicoid] Hyperspectral imaging for brain cancer detection View project
READS

7,216

Universidad de Las Palmas de Gran Canaria

81 PUBLICATIONS 224 CITATIONS

SEE PROFILE 


\title{
Design of a Reconfigurable Li-Ion Battery Management System (BMS)
}

\author{
José Cabrera, Aurelio Vega, Félix Tobajas, Víctor Déniz, Himar A. Fabelo \\ Dept. of Electronics Engineering and Automatics (DIEA) \\ Institute for Applied Microelectronics (IUMA) \\ University of Las Palmas de Gran Canaria (ULPGC), Spain \\ jose.cabrera@ulpgc.es, avega@iuma.ulpgc.es, tobajas@iuma.ulpgc.es, vdgonzalez@iuma.ulpgc.es, hfabelo@iuma.ulpgc.es,
}

\begin{abstract}
In this paper, the design of a Battery Management System for a battery pack composed of Lithium-Ion cells is described. It specifies which lithium-ion technology is used for monitoring control signals such as the high voltage per cell, the start voltage balancing, the low voltage shutdown, and the maximum temperature of battery cells pack. The proposed system allows performing management practices in controlled charging and discharging of batteries.
\end{abstract}

Keywords-Battery Management System (BMS), Metal Oxide Field Effect Transistor (MOSFET), Brushless Direct Current (BLDC), Printed Circuit Board (PCB).

\section{INTRODUCTION}

Nowadays, the implementation of a Battery Management System (BMS) is necessary because of the rising demand for electric vehicles. The main characteristic of BMS is the balance at the charge and discharge process of the battery pack. This increases the lifetime of the batteries and optimizes their performance [1]. In the market there are various technologies of lithium-ion cells with different control voltages, so that by varying only the voltage comparator in the design, it is possible cover almost all existing batteries [2].

\section{BMS HARDWARE DESIGN}

The proposed hardware design consists of an analogic BMS with centralized topology, so that the system has full control of the state of the cells, thus performing tasks of monitoring, protection and remote control over it.

The student develops the BMS schematic determining which type of lithium-ion cell technology will be used to make the layout design later. Finally, the student will manufacture the printed circuit board. In this way, the student will develop all phases of a real project, starting from the initial specifications to the phase of analysis and verification of the right operation of the BMS.

The student must specify which lithium-ion technology will be used, because the four voltage levels necessary for the design of comparators-samplers depend on it:

- Maximum voltage per cell.
- Starting voltage balancing or burned.

- Low voltage disconnecting cell.

- Hysteresis undervoltage shutdown after.

- Maximum temperature of the cell pack.

Once the schematic has been completed and documented we proceed to design and make the printed circuit board. This design includes modules for charging, discharging, balancing by burning excess energy, overcurrent protection, over temperature protection, and communications bus for future expansion.

Fig. 1 shows the location of the BMS in a generic control system. This system consists of a charger, a battery pack, the BMS, a control stage and the system load [3].

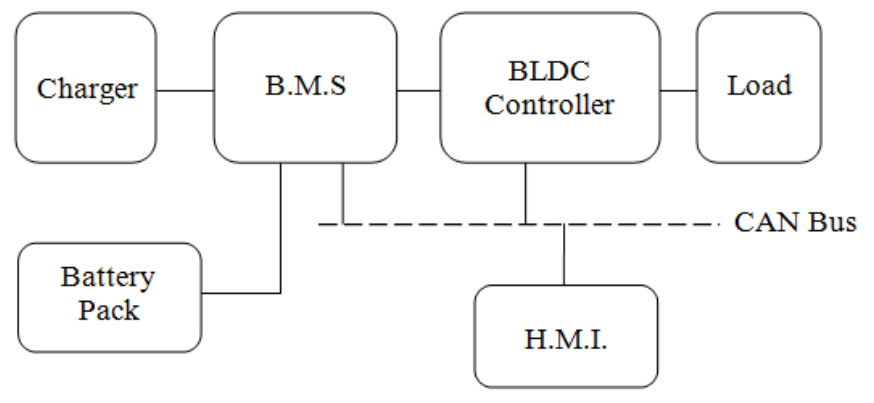

Fig. 1. Full system would be located the BMS

When any cell voltage reaches the maximum load, the BMS should be disconnected from the charger (Fig. 2). The BMS must also balance the cells to maximize their capacity. The system can make the balancing by disabling the load of the cell that holds the greatest voltage until it is low enough so that the charger supplies the load current again. After some cycles of this process, all the cells must be at the same voltage, which would mean that the pack is balanced.

Furthermore, as a cell reaches the minimum cutting voltage allowed, the BMS is disconnected from the load (Fig. 3). 

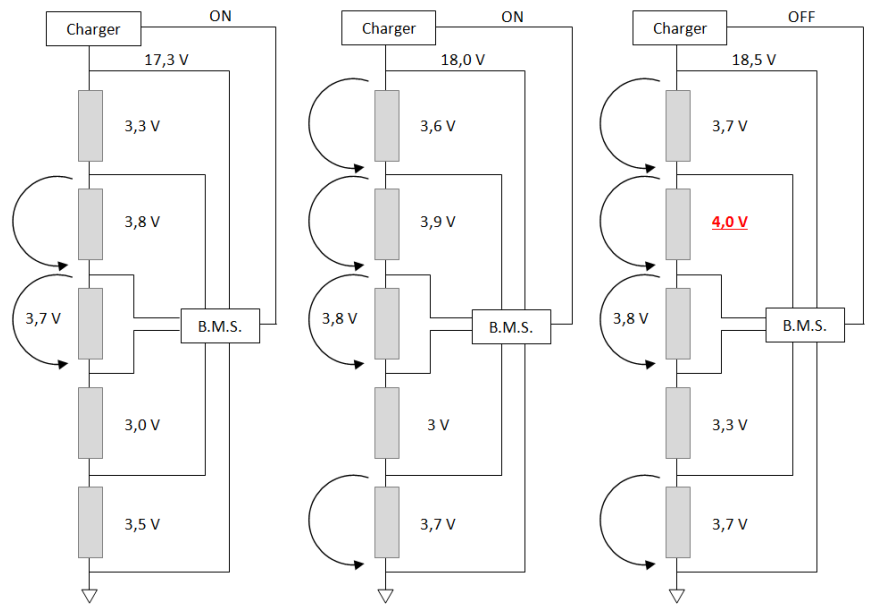

Fig. 2. Battery pack charge process
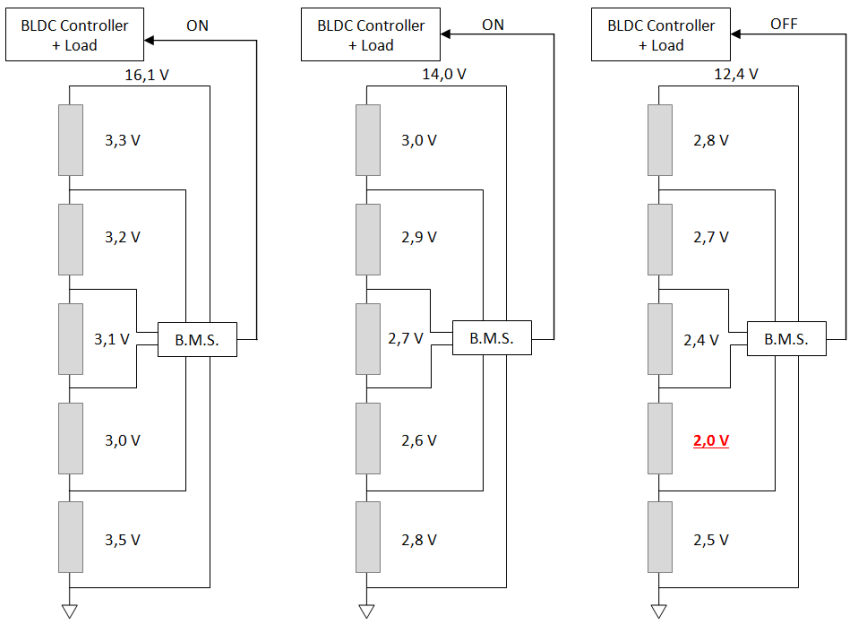

Fig. 3. Battery pack discharge process

\section{CiRCUIT ANALYSIS}

According to the initial considerations to the design of the BMS, its study can be divided into the stages described below.

The full circuit has several parts and each one has its function. All parts are connected to the battery pack. Fig. 4 shows a part of the schematic in which you can see that the cells are monitored by several control circuits at once. The monitoring is performed cell by cell. The connectors marked from B0 to B11 are consecutively connected from cell to cell as they are located in the battery pack

\section{A. Charge Phase}

At the charge phase, is carried out separately the monitoring of critical voltages of each cell. These voltages vary according to the type of technology used in the manufacture of the cells. The choice of the supervisor is based on the voltages, although the BMS can be reconfigured for each technology.

Fig. 6 shows part of the design of the phase in which the monitoring of the two cell control voltages $(2 \mathrm{~V}$ and $4 \mathrm{~V})$ is carried out.
The integrated circuit G4EN monitors these voltages. If the cell voltage is above $4 \mathrm{~V}$, this device stops the charging and activates the burning phase. The cell charging is interrupted by the transistor Q28, which is controlled by the transistors associated with the supervised voltage, in this case, Q2.

a)
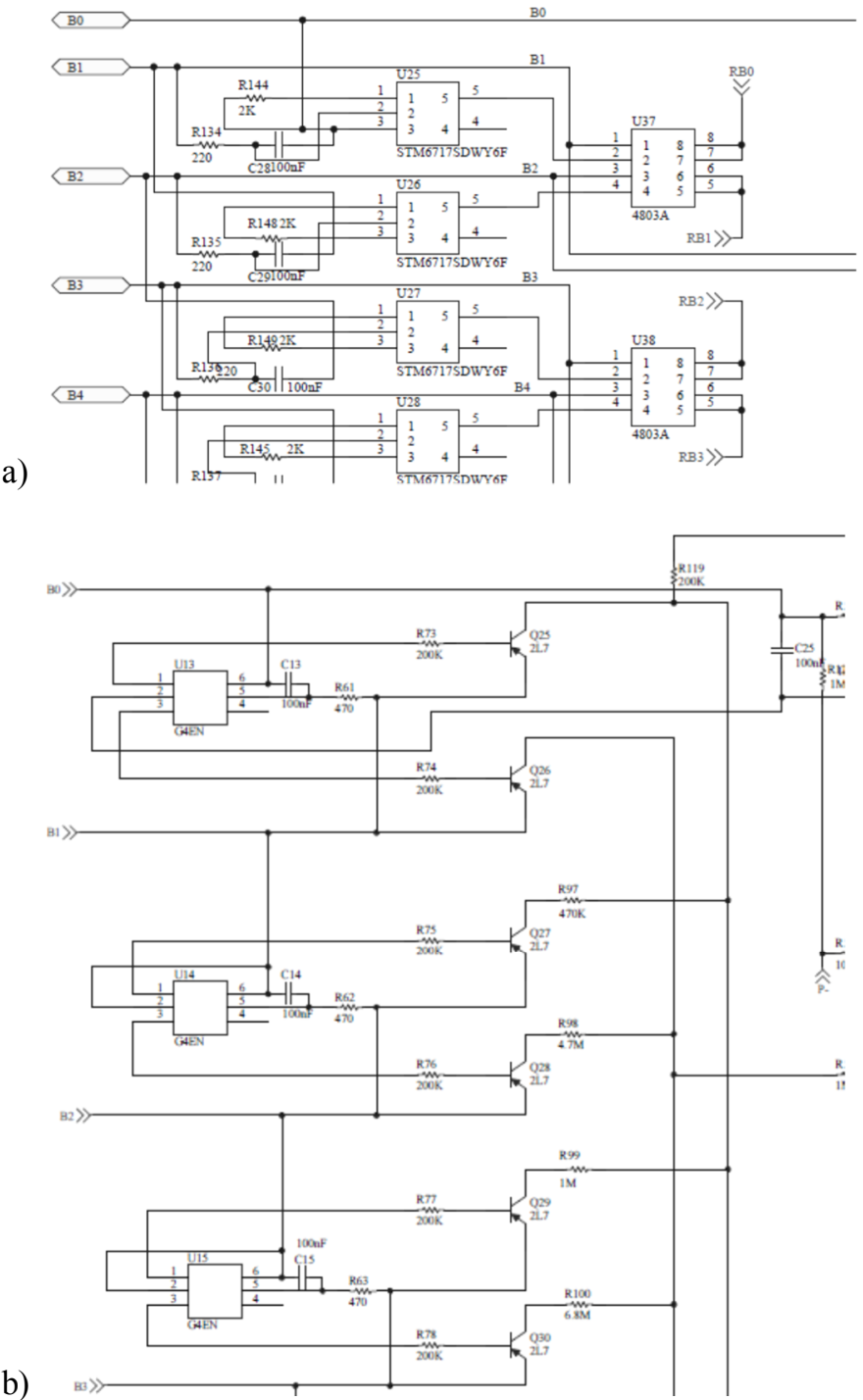

Fig. 4. a) A part of the circuit which carries out, cell by cell, the burning phase b) Minimum and maximum voltage supervisor circuit

The switching stage consists of four n-channel MOSFET transistors in parallel (Fig. 5), which connects and disconnects the charger to the system.

When Q28 (Fig. 6) is switched, it sets the voltage VGS=0 of the MOSFET transistors associated to the load, thus cutting off the conduction of current from the drain to the source $(\mathrm{P}$ $\mathrm{CH}$ ) [4]. If the cell voltage is lower to $3.6 \mathrm{~V}$, then the current will flow again. In this way, any cell will operate with a voltage above the $4 \mathrm{~V}$ set up by the control circuit. 


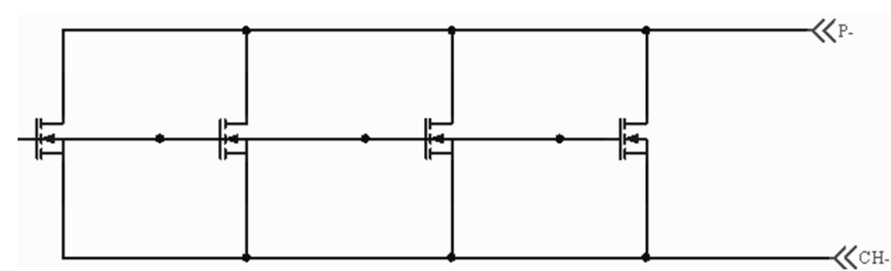

Fig. 5. Switching stage of the BMS

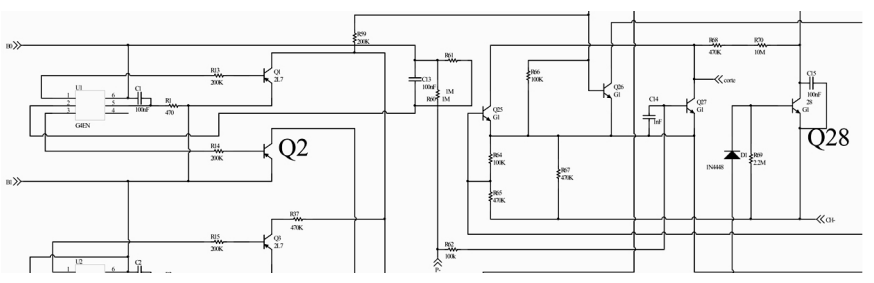

Fig. 6. Charge monitoring circuit

\section{B. Discharge Phase}

Fig. 7 shows the discharge phase of the BMS. The discharge occurs when the BMS is connected to a load, resulting in the discharge of cells. The function of this circuit is to monitor continuously the voltage of each cell and prevent these are below $2 \mathrm{~V}$.

In the discharge process, something similar to the load one occurs: the transistor Q26 is controlled by the transistors associated to the supervision voltage of $2 \mathrm{~V}$ of the G4EN device, Q1 in this case. When the voltage is below $2 \mathrm{~V}$, the transistor Q26 switch off the quartet of MOSFETs disposed between P-and B-, stopping the flow of the discharge current (Fig. 8).

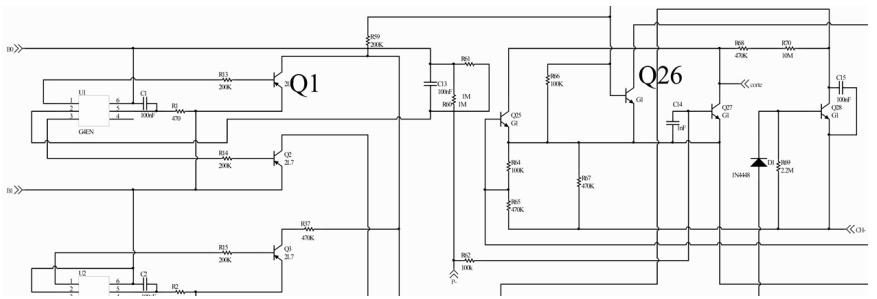

Fig. 7. Discharge supervisor circuit

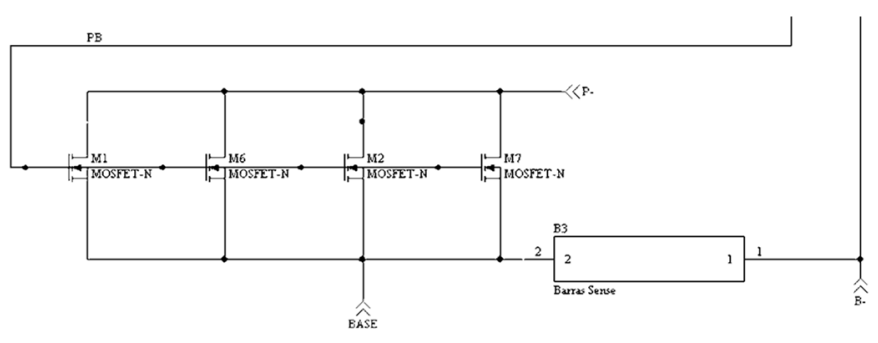

Fig. 8. The power MOSFETs in parallel with high current sensor bar

If a cell voltage is below $2 \mathrm{~V}$, the load of the battery pack will be instantly disconnected, thus preventing any possible error in the process and reducing the inherent risk of destruction of the cell. As the integrated monitoring circuit has a hysteresis voltage of $2.2 \mathrm{~V}$ [5], the intermittent operation of the batteries is prevented.

As a protective measure, and in order to limit the current from the cells that flows by the discharge phase to the output, the BMS includes current monitoring bars. These bars consist of six steel strips between 24 and $30 \mathrm{~mm}$ connected in parallel. Together, they form a total resistance of $3.6 \mathrm{~m} \Omega$, so that taking into account the $\mathrm{VBE}=0.5 \mathrm{~V}$ of the transistor $\mathrm{G} 1$, the sensed current will be about $140 \mathrm{~A}$.

\section{Burning Phase}

Although the cells have been manufactured by the same producer under the same manufacturing process, these are different to each other. These are not been charged or discharged at the same speed, and their lifetime it is not equal. For this reason, the charging system performs a balancing operation thereof.

In the charge phase of the battery pack, a cell balancing process is performed in which, from a certain voltage, the excess of current of each cell is burnt.

This process is performed again and again until all cells are uniformly charged and they reach the maximum voltage value, which depends on the type of technology used. Fig. 9 shows the supervisor that monitors the reference voltage and the associated part for switching the burnt cells (Fig. 10).

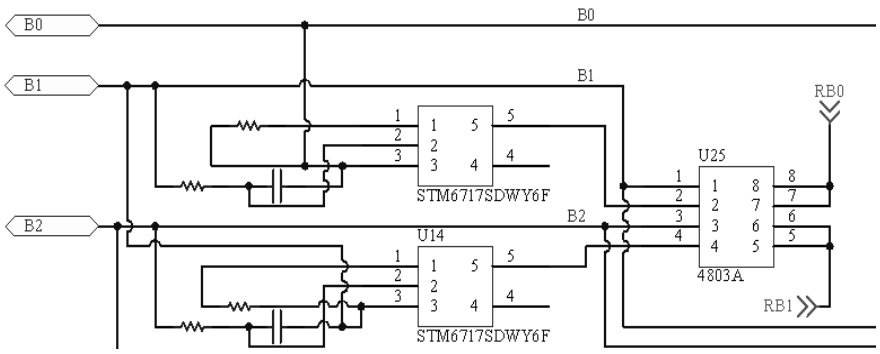

Fig. 9. Supervisor and switch burned

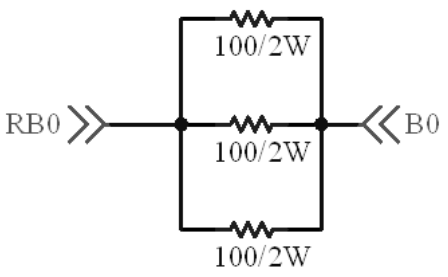

Fig. 10. The burnt cell

\section{Protection Circuit against the Overtemperature}

The temperature of the system, specifically the MOSFET transistors one, is controlled by a thermostat with an encapsulated TO 220. The associated circuit allows it to act both in the charge phase of the battery pack as in the discharge phase (Fig. 11). In this particular case, the monitored control temperature is $80{ }^{\circ} \mathrm{C}$. The transistor Q29 acts on the two gates of the two MOSFETs lines, disconnecting both the charge and the discharge. 


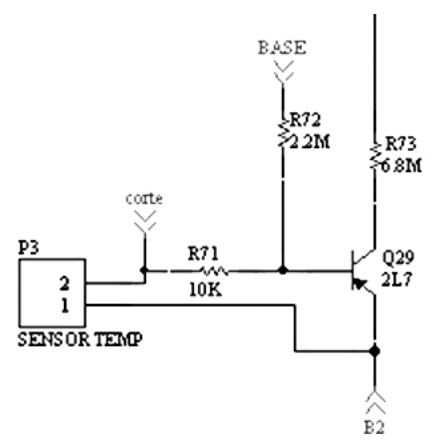

Fig. 11. Temperature sensing circuit

\section{E. CAN BUS Interface}

A completely analogic BMS does not provide the user with the status of the battery pack and the cells, or the remaining capacity of these. However, in a digital BMS, the user can get this information and monitors the charge and the discharge of the battery pack. For this reason, a CAN interface was implemented in order to provide the analogic BMS with some relevant characteristics of a digital one such as:

- Monitoring the voltage of each cell.

- Monitoring the voltage of the battery pack.

- Charging status of each cell (SOC).

- Health status of each cell (SOH).

- Battery Capacity.

This task is performed by a microcontroller, which adapts the output signals to the CAN bus protocol (Fig. 12).

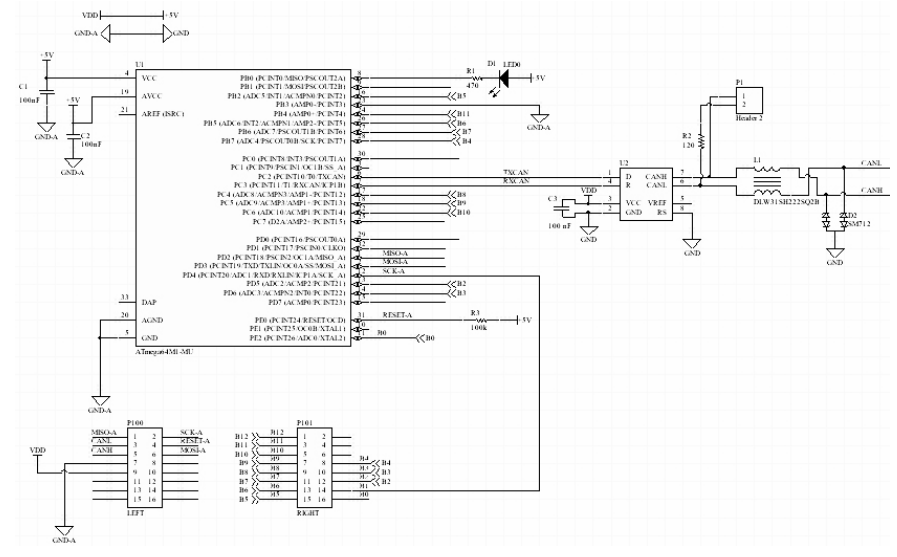

Fig. 12. Bus CAN schematic

\section{Designs of The Printed Circuit BoArds}

The BMS consists of three printed circuit boards:

- The BMS (Fig. 13).

- Burnt resistors (Fig. 14).

- The CAN bus (Fig. 15).

The design of the circuit schematics and the wiring diagram to form the copper tracks was carried out in two phases. First, according to the specifications for the functionality of the circuit, the components and the necessary interconnections between them were established. The wiring diagram was made by the schematic editor of the software. After, the mask, which is a virtual representation of the components on the plate, was defined by the PCB editor. Additionally, the physical form of the connections between the components was established too. To make an electrical or electronic circuit, the designer needs documentation, data sheets from manufacturers and support of computational tools.

\section{A. Techniques for the design of printed circuit boards}

At the process of development and manufacture of electronic prototypes, a previous design of the circuit board must be performed. For this, it is necessary to use special tools and apply theoretical and technical considerations, so that the developer can make and study in detail the models and electronic schemes to be implemented.

The parameters to be considered to design the board are as following:

- The resistive effect of tracks. The tracks must be designed taking into account the length, the thickness and the maximum current which they should lead. Software tools should be used to identify and calculate the dimensions.

- The thermal effect. The location of all components must be studied according to the interconnection and the thermal and electromagnetic interferences.

- The capacitive and inductive effect. The power section must be as far from the control section of the BMS as possible.

- In order to prevent electromagnetic disturbances (EMI) and provide electrical protection, the analogic plane must be separated from the digital one. Also, for this purpose, couplings such as optocouplers, RF isolators, transformers, etc. can be used.

All circuits were integrated under the Single European format, as shown in Fig. 16.

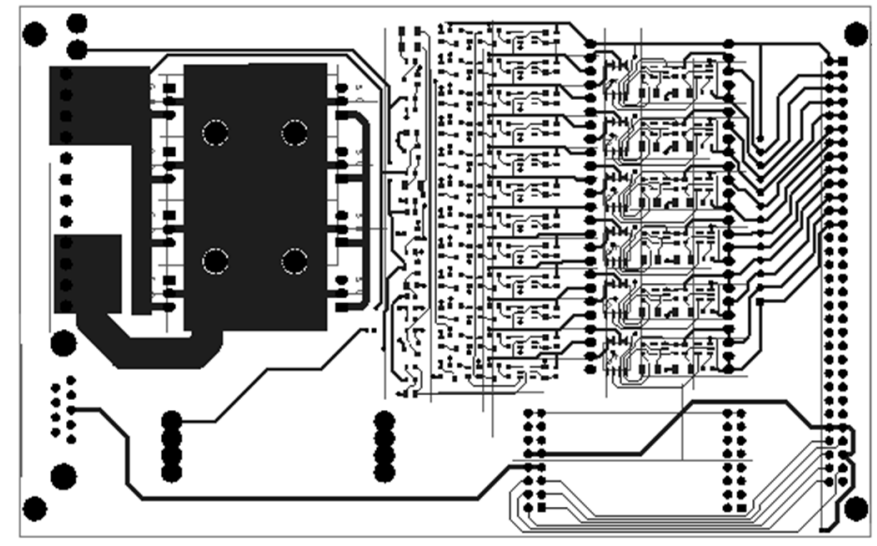

Fig. 13. BMS printed circuit board 


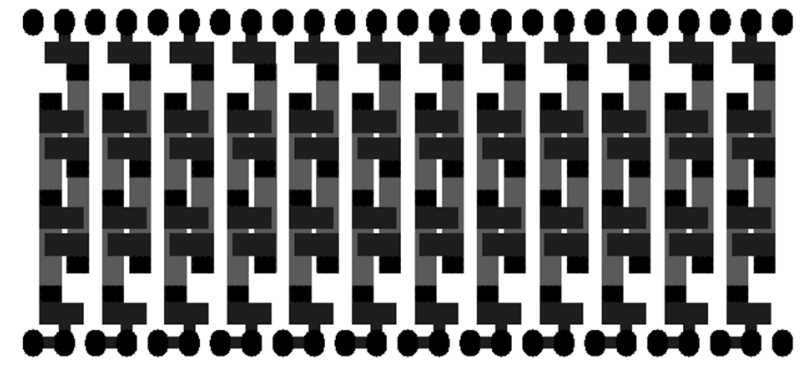

Fig. 14. Burnt printed circuit board

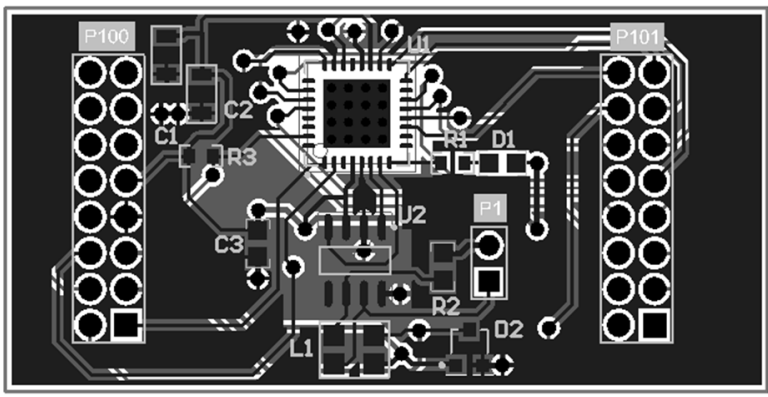

Fig. 15. CAN bus printed circuit board

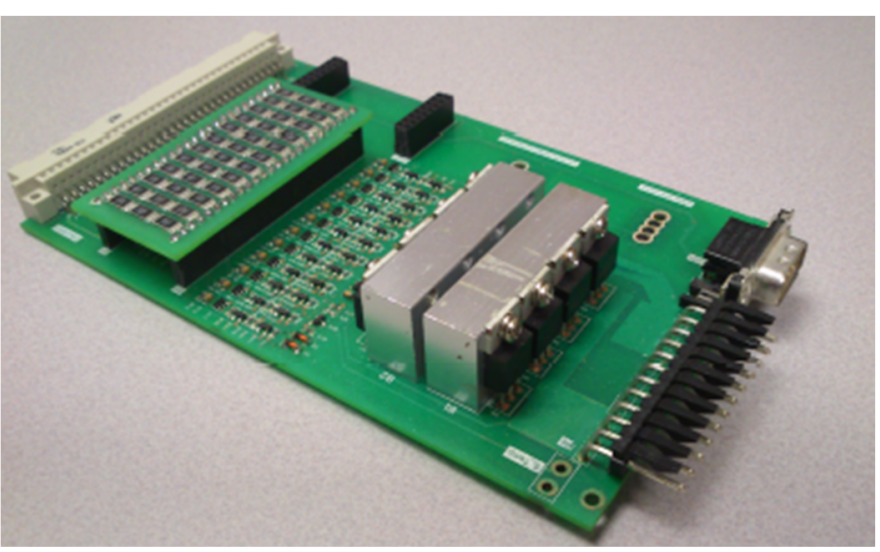

Fig. 16. View of full BMS

\section{TESTS}

In order to carry out the verification of the operation of BMS, a test bench was developed. By this, the status of all cells and the switching between states of charge and discharge, as well as the balancing on the charge phase, were constantly monitored.

\section{A. Discharge Test}

The right operation of the BMS is check by this test. The cells are discharged using a resistive power. If a cell voltage is below $2 \mathrm{~V}$ (the minimum cell voltage, $\mathrm{Vcell}_{\min }$ ), the system is deactivated and it will be reactivated when all cell voltages are above $2.2 \mathrm{~V}$.

Table I shows a discharge process of the battery pack. When a cell voltage is below $2 \mathrm{~V}$ in a battery pack, the system is completely disconnected.

\section{B. Charge Test}

In this test, a current of $2 \mathrm{~A}$ is supplied to the system. The aim of this test is to check that when a cell voltage is $3.6 \mathrm{~V}$ (the burnt voltage, $V_{\text {burning }}$, the excess energy burning process stars, thus balancing the load. When a cell voltage is $4 \mathrm{~V}$, its charge is disconnected, and when it is below $3.8 \mathrm{~V}$, this will be reactivated.

Table II shows a charge process of the batteries through the implemented BMS. When a cell voltage is $4 \mathrm{~V}$, the system is disconnected, but the process of burning the cell voltages that are below $3.6 \mathrm{~V}$ continues.

TABLE I. Discharge PROCESS OF THE BATTERY PACK

\begin{tabular}{|c|c|c|c|}
\hline BMS Status & On & On & Off \\
\hline Time (min) & 0' & $\mathbf{1 0}$ & $\mathbf{7 0}$ \\
\hline Cell & Vcell (V) & Vcell (V) & Vcell (V) \\
\hline B0 & 3,60 & 3,42 & 2,30 \\
\hline B1 & 3,55 & 3,38 & 2,28 \\
\hline B2 & 3,50 & 3,32 & 2,23 \\
\hline B3 & 3,60 & 3,40 & 2,29 \\
\hline B4 & 3,60 & 3,45 & 2,32 \\
\hline B5 & 3,60 & 3,42 & 2,30 \\
\hline B6 & 3,45 & 3,40 & 2,29 \\
\hline B7 & 3,55 & 3,35 & 2,25 \\
\hline B8 & 3,60 & 3,42 & 2,30 \\
\hline B9 & 3,50 & 3,38 & 2,28 \\
\hline B10 & 3,55 & 3,39 & 2,28 \\
\hline B11 & 3,60 & 3,40 & 2,29 \\
\hline B12 & 3,50 & 3,30 & 1,98 \\
\hline Battery pack & 46,20 & 44,03 & 29,31 \\
\hline
\end{tabular}

TABLE II. CHARGE Process OF THE BATteries THROUGH THE BMS

\begin{tabular}{|c|c|c|c|c|}
\hline Time (min) & $\mathbf{0}$ & $\mathbf{1 0}$ & $\mathbf{6 0}$ & $\mathbf{7 0}$ \\
\hline Cell & $\mathbf{V}_{\text {cell }}(\mathbf{V})$ & $\mathbf{V}_{\text {cell }}(\mathbf{V})$ & $\mathbf{V}_{\text {cell }}(\mathbf{V})$ & $\mathbf{V}_{\text {cell }}(\mathbf{V})$ \\
\hline B0 & 2,30 & 2,47 & 3,39 & $\mathbf{4 , 0 1}$ Off \\
\hline B1 & 2,28 & 2,45 & 3,37 & 3,57 \\
\hline B2 & 2,23 & 2,40 & 3,32 & 3,52 \\
\hline B3 & 2,29 & 2,46 & 3,38 & 3,58 \\
\hline B4 & 2,32 & 2,60 & $\mathbf{4 , 0 2}$ Off & 3,90 \\
\hline B5 & 2,30 & 2,49 & 3,39 & 3,59 \\
\hline B6 & 2,29 & 2,47 & 3,38 & 3,58 \\
\hline B7 & 2,25 & 2,46 & 3,34 & 3,54 \\
\hline B8 & 2,30 & 2,42 & 3,39 & $\mathbf{4 , 0 1}$ Off \\
\hline B9 & 2,28 & 2,47 & 3,37 & 3,57 \\
\hline B10 & 2,28 & 2,45 & 3,37 & $\mathbf{4 , 0 1 ~}$ Off \\
\hline B11 & 2,29 & 2,45 & 3,38 & 3,58 \\
\hline B12 & 1,98 & 2,46 & 2,98 & 3,18 \\
\hline Battery pack & 29,31 & 31,62 & 44,08 & 47,91 \\
\hline
\end{tabular}




\section{CONCLUSIONS AND ONGOING WORK}

A version of the proposed BMS for charging the battery of an electric motorbike was made for a Master Thesis, thus showing how this kind of system performs. This project was implemented in the Power Electronics courses taught by the Department of Electrical Engineering and Automation in various degrees of the University of Las Palmas de Gran Canaria (ULPGC).

This BMS is being used in conjunction with a controller for a BLDC motor (Fig. 17) mounted on a test bench (Fig. 18).

Thanks to this design, students can acquire the knowledge and the skills necessary for the complete development of a Battery Management System. They can also analyse the initial specifications and determine the best topology to use in each case. Moreover, students learn to manufacture and assembly the PCBs, and to analyse the data.

Based on this project, a BMS digital will be developed in the future to facilitate the interconnection with other devices and perform the monitoring tasks by a microcontroller. This system allows to program different control signals according to the technology used to manufacture the lithium-ion cells.

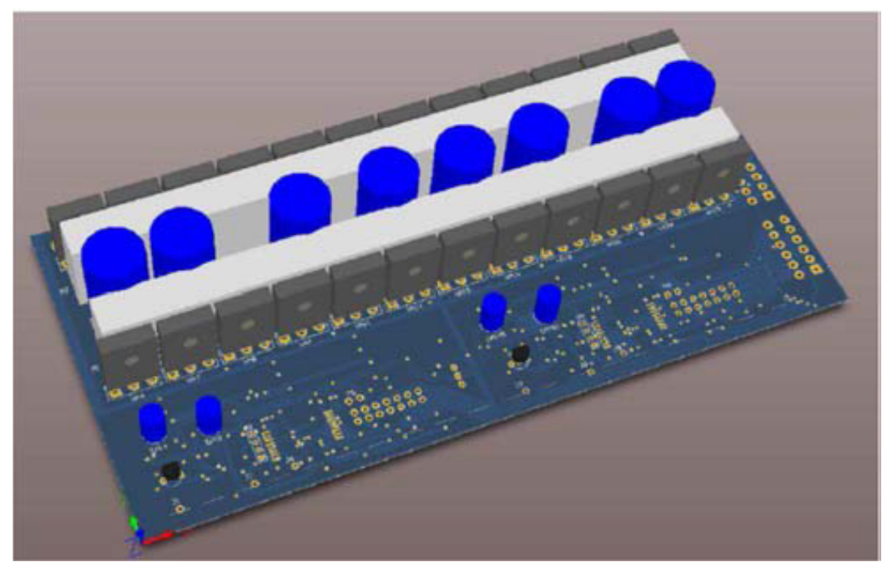

Fig. 17. 3D front view of the controller for 6-phase BLDC motors

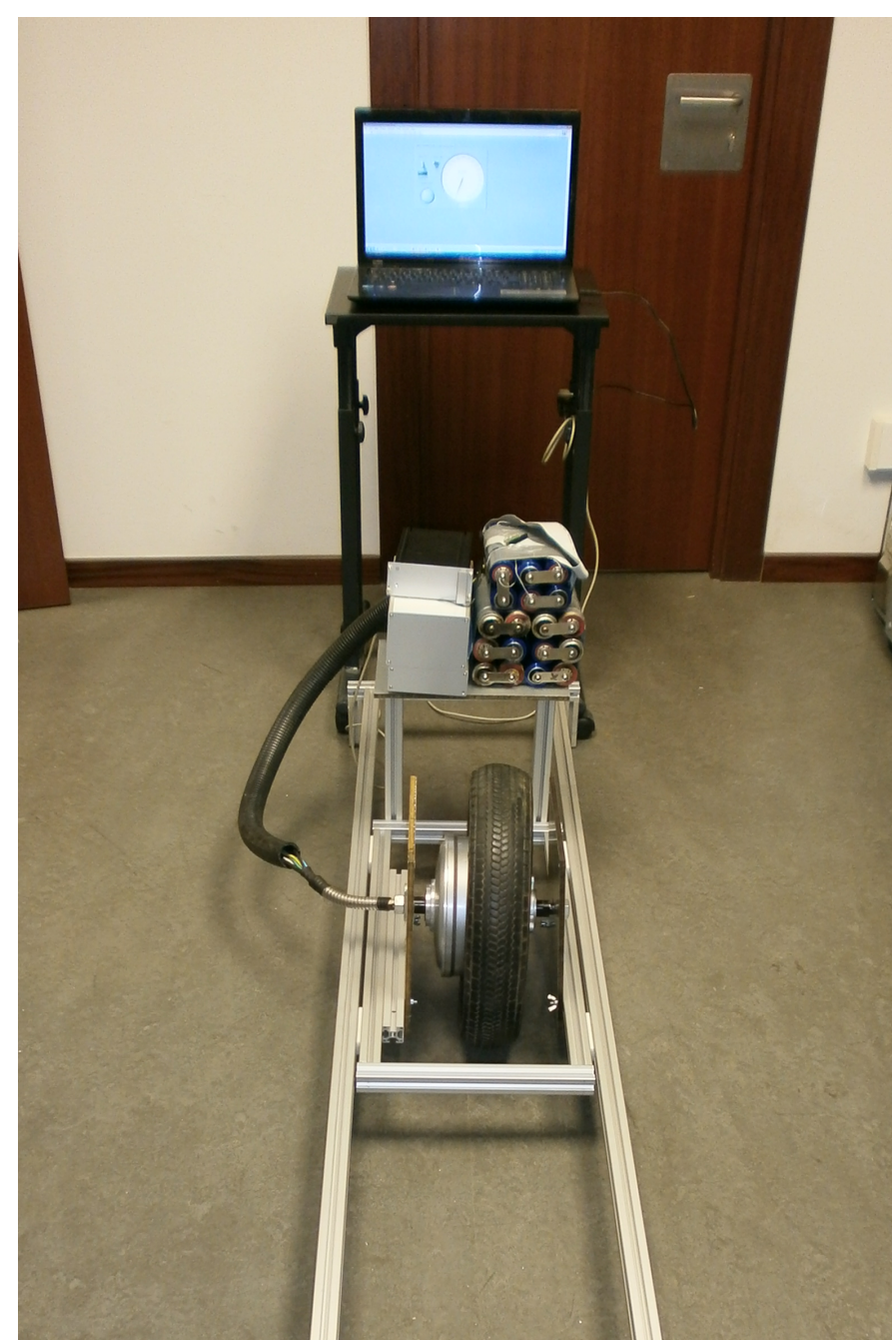

Fig. 18. Test bench of BLDC motors

\section{REFERENCES}

[1] Battery Management Systems for large lithium-ion battery pack. Davide Andrea, Artech House Inc; Edition: New. (September 1, 2010)

[2] Linden's handbook of batteries. McGraw-Hill Professional; Thomas B. Reddy, 4 edition (October 27, 2010)

[3] Designing a New Generalized Battery Management System. John Chatzakis, Kostas Kalaitxakis, Nicholas C. Vulgaris, and Stefanons N. Manias, Senior Menber, IEEE Transactions on Industrial Electronics, Vol. 50, No. 5, October 2003

[4] Electrónica de Potencia. Daniel W. Hart, First edition. Prentice Hall.

[5] Battery Management System Based on Battery Nonlinear Dymanics Modeling, Antoni Szumanowski and Yuhua Chang. Vehicular Transaction On. May 2008 